\title{
Surplus Labour and Lewis Turning Points in China
}

\author{
Xiaobing Wang Nick Weaver*
}

\begin{abstract}
It has been widely recognized that China has had a large pool of surplus labour. However, despite its significant implications for wage levels and the Chinese economy, the current debates yield conflicting results as to whether the Lewis turning point has been reached. This paper clarifies a theoretical issue about the mechanisms of surplus labour absorption, subsequently indentifies two Lewis turning points, and examines the factors that affect the reaching of these two Lewis turning points. It then applies the framework to China to study the labour absorption process and examines the implications of the removal of the Hukou system in terms of welfare and economic performance.
\end{abstract}

JEL classification: J31, 011, O12, O41, O53

Keywords: Dual economy, surplus labour, Lewis turning point, China

\footnotetext{
* Xiaobing Wang, Economics, School of Social Sciences and Centre for Chinese Studies, The University of Manchester, Oxford Road, Manchester M13 9PL. Email: Xiaobing.Wang@manchester.ac.uk, Tel: +44 (0) 161275 4871. Nick Weaver, Economics, School of Social Sciences, The University of Manchester, Oxford Road, Manchester M13 9PL. Email: nick.weaver@manchester.ac.uk, Tel: +44 (0) 161275 4835. The authors thank Xiaolan Fu, John Knight, Jun Li, Xiaohui Liu, Xiaming Liu, Xianglai Sun and the participates at the CEA 2011 Dublin conference for valuable comments and suggestions. Xiaobing Wang thanks the Centre for Chinese Studies Research Fund for financial support.
} 


\section{Introduction}

The existence of a large pool of surplus labour in China has been widely recognized (Knight and Song 1999, 2005, Kwan 2009). The resulting relatively cheap labour has been the main source of China's comparative advantage in the global economy. Based on this comparative advantage, China has adopted a labour-intensive industrialisation strategy led by the export sector, which has helped the Chinese economy to grow at around 10 percent per year (Lin, Cai and Li 2003).

However, there have been reports of labour shortages in some areas of China recently, leading to a debate about whether a Lewis turning point has been reached. Garnaut and Li (2006) edited a book The Turning Point in China's Economic Development discussing China's economic transformation. The China Economic Journal published a special issue (Volume 3, Issue 2, 2010) debating the Lewis turning point in China. The China Economic Review also published a special issue applying the Lewis model to China focusing on the Lewis turning point (Volume 22, Issue 4, 2011). Together these papers, among others, provided a wide ranging review of the existing literature on whether China has reached a Lewis turning point.

The answer to whether China has reached a turning point has important implications for wage levels and competitiveness, but the current debate has yielded conflicting results depending on the method of estimation that was used. Golley and Meng (2011) summarise the current literature as "a range of methods and data have been used to claim that China has already reached the turning point in economic development, yet a range of methods and data have also been used to claim that it has not." Most of the literature looking at the demand side answer "yes" to the question as to whether the Lewis turning point has been reached: the reason offered being the sustained increases in the urban sector wage in recent years. In contrast, literature looking at the supply side gives a "no" answer with their reason being the continued existence of a large amount of rural surplus labour. This raises the puzzling problem of the co-existence of migrant labour shortage and rural labour surpluses in China. There have been some studies attempting to explain the puzzle and they have offered some very interesting explanations.

Knight, Deng and Li (2011) argue that there is segmentation in the labour market - the result of constraints on rural-urban labour migration, such as the Hukou system, means that although rural labourers are in surplus, they cannot move easily to urban areas where labourers are in short supply. Chan (2010) argues that there are many labour supply curves in a real economy, for example, there is structural mismatch of young and old workers - China's urban sector is in need of young workers who are in short supply whilst it is old workers who have stayed in rural areas that are in surplus. Garnaut (2010) relates this phenomenon to geographically differentiated labour markets, imperfect mobility of labour between regions and different standards of living across provinces. As a result Garnaut argues that we should think in terms of a "turning period" instead of a "turning point".

There are two major gaps in the literature that need to be addressed. First, theoretical issues related to mechanisms of surplus labour absorption and the nature of the Lewis turning point need to be clarified. Many datasets have been constructed and different estimation techniques used to investigate the question but the theoretical understanding 
of the labour transition dynamics has been relatively weak, ambiguous, lacking accuracy, and even confusing. Second, because labour market mobility in China is complicated by the household registration (Hukou) system, the relationships between Hukou and the Lewis turning point need to be better understood.

Building upon Wang and Piesse (2011), which provides the microeconomic foundations for the dual economy models, this paper firstly identifies two Lewis turning points and examines the factors that affect the reaching of these two Lewis turning points. Secondly, this framework with its two turning points is applied to China to study the labour absorption process and the implications of a possible removal of the Hukou system for economic performance and welfare.

This paper does not attempt yet another estimation since the existing literature has already provided many interesting results rather this paper tries to bridge the gaps in the existing literature and offer a way to link them together with the hope of providing a more holistic understanding of labour market issues in China.

This paper contributes to the literature in the following main aspects: first, it clarifies a theoretical issue on labour market transformation by providing micro foundations for the two Lewis turning points and clearly indentify the implications of these for the labour market and wage levels; second, it applies the two turning points reasoning to demystify the puzzle about the coexistence of Chinese surplus labour and increasing wages; third, it establishes that the process of approaching the Lewis turning points is a dynamic and non-linear processes by identifying some of the most important factors affecting the reaching of the turning points.

The paper is structured as follows. The next section reviews some microeconomic foundations of the dual economy models and establishes the theoretical foundations of two Lewis turning points. Section 3 examines the factors that affect the reaching of these Lewis turning points; Section 4 reviews the current debate; section 5 discusses the welfare implications of the possible removal of the Hukou system. The final section concludes.

\section{The micro-foundations of Lewis turning points}

Some features of dual economies have been modelled by Lewis (1954) and Fei and Ranis $(1964,1997)$ and many others. But most of these macroeconomic approaches lacked detailed microeconomic foundations and this led to much confusion and arguing at cross purposes. Wang and Piesse (2011) provided comprehensive microeconomic foundations for these dual economy models which clarified many of the issues. This section draws heavily upon the results of Wang and Piesse (2011).

In the simple dual economy model introduced in Lewis (1954), there are two sectors: these may be identified as the agricultural sector and the industrial sector. For simplicity, we assume that the agricultural sector is in rural areas, and the industrial sector is in urban areas. ${ }^{1}$ Labour in the agricultural sector is plentiful, frequently having a zero or extremely low marginal productivity. This is the source of surplus labour. Labour in the

\footnotetext{
1 The two contrasting sectors are also called subsistence and modern sector in this paper. See Wang and Piesse (2011) for more details on the classification of the two sectors.
} 
industrial sector has, in contrast, a positive marginal product. There is an income gap between the two sectors this provides surplus labour in the rural areas with an incentive to migrate to the urban areas.

In the industrial sector, in general firms can be presumed to follow a profit-maximization principle in order to survive in the competitive market. These firms employ people to a level where the wage workers receive equals their marginal product. ${ }^{2}$ The agricultural sector employs all the labourers that were unable to find employment elsewhere. Surplus labour can exist in the traditional agricultural sector because this sector normally uses family units as the basis for organising production and shares output rather than allocating it on the basis of marginal productivity. The agricultural sector thus acts as a "sink" for the industrial sector.

The population in the rural sector is sufficiently high that there is effectively an unlimited supply of labour able to move to the urban sector without lowering agricultural output. This unlimited supply of labour from the rural sector keeps wages in the urban sector low, ensures that capital accumulation in the urban sector is sustained over time, and thus leads towards a quicker economic transformation to a modern economy.

The main feature of the rural agricultural economy is that it mainly consists of family units engaged in agricultural production. All family members share the work and the subsequent output. No family members are denied food. This intra-family distribution principle enables those surplus labourers to be supported while their marginal product $(M P L)$ is lower than their subsistence needs ${ }^{3}$.

Looking at these issues Lewis (1954) and his subsequent work provided a macro level conceptual framework, which was formalised by Ranis and Fei (1961) and Fei and Ranis $(1964 ; 1997)$. They describe three stages of labour transfer defined by the marginal productivity of agricultural labour. Wang and Piesse (2011) explicitly define two types of surplus labour and give a theoretical foundation for empirically studying the path of labour market transformation in economies at their early stage of development.

Wang and Piesse (2011) define two types of surplus labour. If a labourer's MPL is equal to or less than zero, s/he is called Type I (absolute) Surplus Labour. That is, when $M P L \leq 0 \leq w$, where $w$ is the real wage of a labourer. Labour is defined as Type II (relative) Surplus Labour if the $M P L$ is greater than zero but lower than the actual wage received, that is, when $0<M P L<w$. After this, we can rewrite the three stages of labour transfer as follows: stage I is when there exists type I (absolute) surplus labour; stage II is when there exists type II (relative) surplus labour. Stage III is when there is no surplus labour.

\footnotetext{
${ }^{2}$ If this sector were to employ all the surplus labour - this would require a lower wage, than the neoclassical "wage equals marginal product" solution. This may drive remuneration below subsistence levels of consumption, which means that full employment by the industrial sector is not possible.

${ }^{3}$ Ideally, there should be a distinction between the supply prices of migrants maximising own income (wage must be above household income per capita) and those maximising household income (wage must be above household marginal product of labour). This distinction has big implications on the initial migration but as the discussion of Lewis turning points concerns later stage of migration, this paper does not distinguish the two for simplicity.
} 
After defining two types of surplus labour and three stages of labour transfer, the two turning points, which divide the three stages can be stated: A Lewis Turning Point I is defined as one when type I (absolute) surplus labour is exhausted (MPL approaches a positive value), and a Lewis Turning Point II as one when type II (relative) surplus labour is exhausted (MPL approaches the real wage they get paid). ${ }^{4}$

In the first stage, when there is an unlimited supply of labour, the modern sector wage is constant. Then when all type I surplus labour is absorbed by the modern sector, the economy passes the first Lewis turning point and enters stage II. In stage II the modern sector wage starts to increase. When type II surplus labour has been exhausted and the economy passes the second Lewis turning point into stage III. After entering stage III the wage in the traditional sector also begins to increase. ${ }^{5}$ This is the point when the traditional sector starts to compete for labour with the modern sector at a rate that is determined by neoclassical demand and supply principles. The economy now can be modelled by a neoclassical one-sector theory.

It might help to clarify using Diagram 1 which illustrates two types of surplus labour and three stages of labour transfer in terms of agricultural sector labour productivity.

$<$ Insert Diagram 1 here>

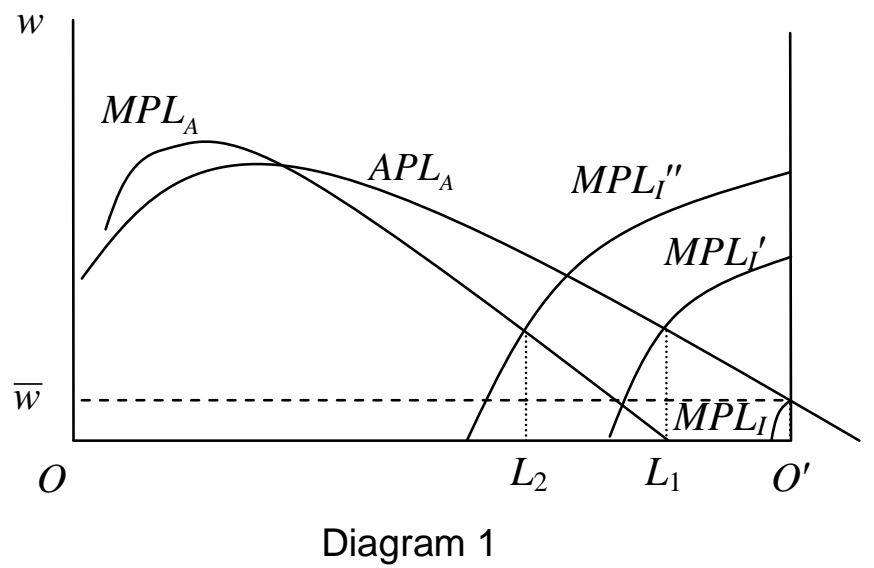

The horizontal axis, $O O^{\prime}$, shows the amount of labour in the economy, which can be assumed to be fixed when there is no population/labour growth. The agricultural sector labour is measured rightwards from the origin $O$. The $M P L_{A}$ and $A P L_{A}$ curves are the marginal and average product of labour in the agricultural sector respectively. Industrial employment is measured leftwards from $O^{\prime} . M P L_{I}$ curve is the marginal product of

\footnotetext{
${ }^{4}$ Since there was no clear distinction between the two different types of surplus labour and the two turning points in the previous literature, which of the two turning points is the Lewis turning point is ambiguous. Fei and Ranis (1997) refer to the second turning point as the Lewis turning point, but much of the literature refers to the first as the Lewis turning point instead. Therefore, in discussing the exhaustion of surplus labour, the types of surplus labour must be clarified, and in the discussion of an economy approaching the Lewis turning point, the specific turning point being referred to must also be clarified, since this has significant implications in terms of differences in the likely rate of change of wages.

5 To be precise, the wage in the traditional sector begins to increase in stage II if there is no labour growth in that sector. This scenario is studied in later section.
} 
labour in the industrial sector. When the industrial sector expands, the $M P L_{I}$ curve moves to the left. ${ }^{6} \bar{w}$ is the subsistence level of output per capita (wage), and is also the average product of labour in the steady state (in the Malthusian equilibrium). ${ }^{7}$ At the initial stage, because the industrial sector is small, the $M P L_{A}$ and the $M P L_{I}$ do not intercept with each other. In the later stage when the industrial sector expands, it moves to $M P L_{I}{ }^{\prime}$ and intercepts with $M P L_{A}{ }^{8}$

As in Diagram 1, initially, everybody is in agriculture sector and is paid $\bar{w}$. The agricultural sector absorbs all the surplus labour which is $L_{2} O^{\prime}$. In a scenario without population/labour growth, $O^{\prime} L_{1}$ is type I surplus labour (because for these labourers, $M P L \leq 0 \leq w)$ and $L_{1} L_{2}$ is type II surplus labour (because for these labourers, $0<M P L<w)$. Because of the differences in real income, agricultural sector residents have incentives to migrants to industrial areas. In this diagram, statically, $L_{1}$ is the Lewis Turning Point I and $L_{2}$ a Lewis Turning Point II.

\section{Dynamics of two Lewis turning points}

Because the Lewis turning points are just transition points between different stages, both the supply dynamics for agriculture sector and the demand dynamics from the industrial sector can affect the stages and the position of an economy. Many factors have to be taken into consideration when estimating the stages of economic development and whether particular Lewis turning points have been reached. There is not a linear and/or smooth transition/progression towards Lewis turning points. Incremental and sudden changes due to external shocks can speed up, slow down or even reverse the process.

There are two driving forces that determine the amount of surplus labour and affect the transfer of labour from the traditional to the modern sector: supply side and demand side. On the demand side, the patterns of industrial expansion, in terms of its employment, and the speed of its expansion all have very big implications on the reaching of the turning points. However, our focus here is the supply side, where the $M P L$, the $A P L$ and the rate of technical change in the traditional sector all determine the amount of labour that can be released.

As the agricultural sector has to be able to produce enough food for the population to survive and sustain. The transfer of type I surplus labour does not have significant impact on it because the $M P L$ of those labourers is zero anyway, however, the transfer of type II surplus labour is possible only if agricultural sector is sufficient to produce enough food for the full population. Agricultural productivity sets as a constraint for the transfer of surplus labour.

In the absence of labour transfer, the increase of the agricultural total factor productivity $(T F P)$ will create more surplus labour in the traditional sector. If the rate of emigration is in line with the rate of TFP increase in the traditional sector, the total amount of surplus labour will be constant in the traditional sector; if the rate of TFP increase is

\footnotetext{
${ }^{6}$ We assume that the industrial sector expands with employment expansion. That is, for simplicity, we do not consider jobless growth.

7 We assume, again for simplicity, there is no food constraint. That is, the urban industrial sector can supply its own food.

${ }^{8}$ We also assume, again for simplicity, but this assumption will be relaxed later, that the productivity in agricultural sector does not change.
} 
quicker than the rate of transfer, the total amount of surplus labour will increase.

When surplus labour is constant or increasing, the wage will not increase, and the modern sector will have an unlimited supply of labour from the traditional sector at a constant wage level. In this case, the position of an economy will not move towards the Lewis turning points.

If the emigration rate from the agricultural sector is smaller than the rate of population growth in that sector, the agricultural sector will always have surplus labour, and the industrial sector can always pay a subsistence wage for this labour. The Lewis turning points will not be reached. If industrial sector employment grows faster than the population growth in the agricultural sector, the share of population in the agricultural sector will fall and that in industry will increase. The Lewis turning points will be reached. That is, the ability to create employment in the modern sector is dependent on both the rate of modern sector expansion and its absorptive capacity. ${ }^{9}$

The dynamics of labour transfer from the rural sector to the urban sector can also be described in Diagram 2, which is a modified based on Diagram 1.

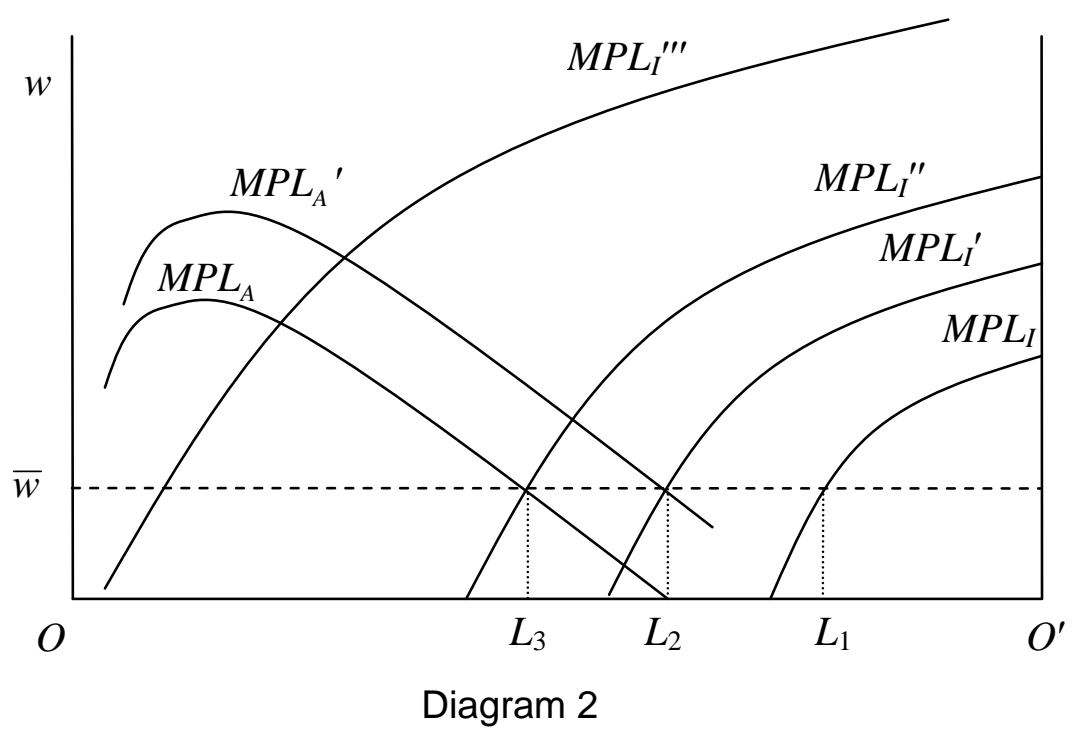

The $M P L_{I}$ curve is the marginal product of labour in the modern industrial sector. $M P L_{I}^{\prime}, M P L_{I}^{\prime \prime}$ and $M P L_{I}^{\prime \prime \prime}$ represent different stages of industrial development. The modern industrial sector that emerges is small at the beginning and requires some labour which it is able to take from the pool of surplus labour in the traditional agricultural sector. Up to $M P L_{I}^{\prime}$, all labour transferred is type I surplus labour. Their marginal product in agriculture is zero or negative, but when they transfer to the modern sector, their marginal product becomes positive. Although wages are still at subsistence level, this is a net contribution to the economy and a Pareto gain is made from this transfer.

When type I surplus labour is transferred out of the traditional agricultural sector, the

\footnotetext{
${ }^{9}$ How much the modern sector expands in output and/or employment depends on the nature of technological change, the division of labour, the demand for its output and its terms of trade with respect to the traditional sector.
} 
average product of labour in agriculture will rise. In the very long run if population is dynamically allowed to adjust, this will cause a population increase, and $O^{\prime}$ will be moved further to the right, until again $A P L$ reaches the subsistence. This will not affect productivity in the modern industrial sector, but the agricultural sector will absorb all the increased population. ${ }^{10}$ That is, the population growth will replace labour that has transferred and the same level of surplus labour will exist at the same level of per capita income.

In diagram 2, the rate of growth of employment in the modern industrial sector is the speed of the shift of the $M P L_{I}$ to the left. If this is slower than the move of $O^{\prime}$ to the right this means that the migration rate is smaller than the rate of population growth in the traditional sector. In this case, the agricultural sector will always have surplus labour, and the industrial sector always pays a subsistence wage for this labour. If industry grows faster than the population growth, that is, the speed of the shift of $M P L_{I}$ is greater than the speed of the move of $O^{\prime}$ to the right, then the share of population in the agricultural sector will fall and that in industry will increase.

If the move of $M P L_{I}$ in the horizontal direction on the diagram is defined as the difference between the number of migrants and the rise in population, then the change in population can, for simplicity, be ignored in this discussion. As industry expands, $M P L_{I}$ moves upwards and to the left as migration increases until $M P L_{I}^{\prime}$ is reached, at which point type I surplus labour is exhausted in the agricultural sector. Before this point, the transfer only depends on the absorptive capacity of the industrial sector and the supply of agricultural output is not a constraint. When industry expands further beyond $M P L_{I}^{\prime}$, the marginal product of labour in the agricultural sector becomes positive although still lower than the subsistence wage. Between $M P L_{I}^{\prime}$ and $M P L_{I}^{\prime \prime}$ there is type II surplus labour transferring out of agriculture. This will not only be determined by the growth of the industrial sector, but also by the development of the agricultural sector. The transfer will not be possible, because if people with positive marginal product of labour transfer out, the total output and average output of agricultural goods will drop below subsistence level. The necessary condition for type II surplus labour to be transferred out is for technological change in the agricultural sector to increase the marginal product of the remaining labour, making them able to produce sufficient output for both sectors. This is where the role of agriculture becomes important, as discussed in the previous section. In the diagram, the $M P L_{A}$ has to shift upwards and to the right to a new curve, $M P L_{A}{ }^{\prime}$. The wage the industrial sector offers should not be lower than the subsistence level plus their original marginal product. So now, the industrial sector wage for type II surplus labour has to be higher than the subsistence level as this was type II surplus labour in the agricultural sector before technological change. Without faster expansion of the industrial sector, labour would stay in agriculture and become type I surplus labour. But now, with the joint forces from industrial sector expansion and agricultural technological improvements in the traditional sector, they change from the original type II surplus labour to a competitive labour force. After this point, the labour market becomes competitive, the industrial sector has to pay higher wages than the subsistence level, with the wages determined by

${ }^{10}$ It is in this sense that the agricultural sector is known as the sink for surplus labour. 
the intersections of the $M P L_{I}$ and the $M P L_{A}$.

\section{Surplus labour and rising wage in China}

Let us now have a closer look at the reality of the labour market in terms of labour supply and wages in China.

In terms of wages, it is generally agreed that there was a constant wage for unskilled workers in urban areas for a period of around twenty years before the early 2000s. The debate is about subsequent wage behaviour and in particular whether urban and rural wages started to increase after that period. Cai and Wang (2008) and Cai (2010) found significant wage increases for unskilled labour in urban sector especially in coastal urban areas. They argued that the noticeable increase in rural migrants' wage rate indicates a shortage of unskilled labour in some of China's costal urban areas, and the exhaustion of China's surplus agricultural labour. They use evidence on wage increases in urban areas to imply labour shortages in the rural sector. This observation led them to believe that China had reached a Lewis turning point in 2006.

Using micro level data in six provinces, Zhang, Yang and Wang (2011) found significant increases in the rates of wage growth in representative rural areas after 2003 even when the periodicity of agricultural work was taken into consideration. The rapid rise of real wages rate in even in remote areas led Zhang et al (2011) to believe that the era of surplus labour is over and that the Lewis turning point in rural China arrived in 2003. They take the evidence on wage increases in rural areas to imply labour shortages in rural areas.

In contrast to these studies of wage patterns, other studies find that China still has a large pool of underutilised labour in the countryside. Kwan (2009) estimated that there were still 166 million, accounting for 52 percent of total rural labour, that can be classified as surplus labour in the Chinese agriculture sector. These workers do not have enough work to do in the rural sector. Ercolani and Zheng (2010) found that the marginal productivity of agricultural labour is still lower than the initial low average productivity of agricultural labour. This implies the continued existence of disguised agricultural unemployment.

It is argued that the rapid growth of real wages may not necessarily be the result of growing labour scarcity. Indeed, Knight et al (2010) find that migrant real wage appears to have risen rapidly on the one hand, but there is still a huge number of surplus labourers in rural areas. They produced evidence based on Chinese Household Income Project (CHIP) data that migrant wages have indeed risen in real terms in very recent years, and that their wages are sensitive to urban labour market conditions and to rural wages. However, the potential pool of migrants barely declined over the five years from 2002 to 2007. They argue that there is a substantial supply of migrants still available in rural China whichever measure is considered.

Further more, Golley and Meng (2011) argues that China still has abundant under-employed workers with very low income in the rural sector. They argue that despite some evidence of rising nominal urban unskilled wages between 2000 and 2009, 
there is little in the data to suggest that this wage increase has been caused by shortages of unskilled labour.

From the above estimations we can see a clear pattern that there is labour shortage at a constant wage in urban areas, and wage of unskilled labour in both urban areas and rural areas has risen since 2003. On the other hand, there is huge amount of surplus labour in the rural areas that is underutilised. Many, including Knight et al (2011), have found this puzzling.

Fleisher, Fearn and Ye (2011) explain this in terms of the efficiency-wage hypothesis. That is, the observed wage increase was not because of labour shortages, but because of deliberate decisions in the urban sector in order to promote efficiency. However, this interpretation, would seem unlikely to be able to fully explain the phenomena. Given the size of the increase in wage market forces seem to be a more likely to be the fundamental cause.

Knight et al (2010) explanation of the puzzle is in terms of a labour market segmentation due to constraints on rural-urban labour migration. The institutional constraints create difficulties for migrants living in urban areas-in respect of good and secure jobs, housing, and access to public services - and these deter or prevent migrant workers from bringing their families with them. This in turn makes many rural workers reluctant to leave the village, at least for long periods.

Chan (2010) argues that there are many labour supply curves in a real economy, for example, there is structural mismatch of young and old workers - China's urban sector is in need of young workers who are in short supply whilst it is old workers who have stayed in rural areas that are in surplus. Garnaut (2010) relates this phenomenon to geographically differentiated labour markets, imperfect mobility of labour between regions and different standards of living across provinces. Knight et al (2010) argue that spatial heterogeneity and imperfect labour mobility means that some areas experience labour scarcity before others. The opportunity cost of migrant labour is more likely to rise gently than to jump sharply. So that the supply curve to the urban sector will curve upwards gradually.

Golley and Meng (2011) argue that China's unique institutional and policy-induced barriers to migration have both prevented many rural workers from migrating to cities and also reduced the migrants' length of stay. They project that under alternative institutional settings, the migrant stock could easily be doubled from the current 150 million to 300 million by increasing either the average length of time that migrants stay, or the migrant inflow, or both. To Golley and Meng (2011), the impact of China's institutional settlings is not only affecting the level of current migrants but, but is also deterring potential future migration.

From the theoretical discussion in the previous section it should be clear that up to the first Lewis turning point, the benefit of economic growth is in the form of the absorption of type I (absolute) surplus labour with a constant wage. Between the first Lewis turning point and the second Lewis turning point, wages start to rise as the marginal productivity of labour (the opportunity cost) becomes positive. At this stage, one would expect to observe an increasing wage in both the industrial and agricultural sectors while surplus labour in the agricultural sector still exists. As type II (relative) 
surplus labour becomes exhausted, the economy approaches the second Lewis turning point. After the second Lewis turning point, the industrial sector has to compete with the agriculture sector for labour and the economy enters a neoclassical phase.

Based on this, we can see that China has reached the first Lewis turning point. This is supported by the coexistence of surplus labour and increasing wages, a phenomenon that is predicted by our theory. Of course, the situation in China is compounded by the labour market segmentation, reinforced by the Hukou system. That is the above explanations especially Knight et al (2011), Chan (2010) and Garnault (2011) have identified some factors that contributed to the phenomenon of the coexistence of surplus labour and increasing wages. In other words, the coexistence of surplus labour and increasing wages is not a puzzle but a fundamental force. Labour market segmentation only makes things a little more complicated.

\section{On the movement towards Lewis turning points}

This section specifies, and emphasises the importance of, the factors affecting the exhaustion of surplus labour during the movement towards the two Lewis turning points.

There are two driving forces that determine the amount of surplus labour and affect the transfer of labour from the traditional to the modern sector. On the supply side, population growth and the $M P L$, the $A P L$ and the rate of technical change in the traditional sector all determine the amount of labour that can be released. On the demand side, the rate of modern sector expansion and its absorptive capacity determines its ability to create employment. The interaction of these factors is unlikely to lead to a smooth linear movement towards the Lewis turning points.

Population growth has important implications for when the surplus labour will be exhausted. Because surplus labour is the total number of labourers whose $M P L$ is lower than their wage, fast population growth will increase the number of surplus labourers in an economy, others things being equal. The demographic transition has a profound impact on the number of surplus labourer that is available and the timing of reaching the Lewis turning point. For example, the one child policy led to a substantial decline in population growth rates, and has accelerated the onset of agricultural commercialisation. Cai and Du (2011) emphasise the impact of demographic change on the labour situation in China. They suggest that the reduction in population growth will lead to a further tightening of the rural labour supply and this may even threaten China's future growth prospects.

Increases in agricultural productivity would increase the number of workers that are no longer needed in agriculture production. This results in an increase of surplus labourers in the agricultural sector. The Household Responsibility System and other technological improvement such as seeds, crop varieties and the use of fertilizers resulted in an increase in agricultural output by about 50 percent (Lin, 1988). This has led to a jump in the number of surplus labourers.

How much the modern sector expands in output and/or employment depends on the nature of technological change, the division of labour, the demand for its output and its terms of trade with respect to the traditional sector. 
Industrial absorptive capacity relates to the way the industrial sector expands - through employment creation or labour-saving technology. The patterns of technological change in the industry sector matters a lot. It determines whether the expansion will end up with more labour employment or more machines - the so called jobless growth.

Shocks also play a big role here either directly or indirectly. Domestic policy shocks, for example the introduction of the Household Responsibility System, the abolishment of rural agriculture tax, all have implications for the amount of surplus labour. International shocks that affect demand for industrial output have implications for the absorptive capacity of the industrial sector. For example, in the middle of the global financial crisis in January 2009, about 20 million of China's migrant workers returned to the countryside after losing their jobs. Although this return turned out only to be for a brief period, it shows the full force of shocks on the labour market.

\section{Conclusions}

The stock of surplus labour and the state of China's labour market have important implications for the Chinese economy. If China is entering a new era of labour shortage, China's labour-intensive and export-driven growth model will gradually lose its competitive advantage. China will have to reorient its development strategy toward labour practices that are more capital intensive and based on labourers' skills (Zhang et al 2011). However, if China is not near to the point were it begins to run out of surplus labourers then policy makers may be basing their decision on a serious misconception. This may lead to the premature abandoning of the labour intensive development model with the associated rise of unemployment and poverty.

One way of thinking about the state of China's labour market is whether the Lewis turning points have been reached. The importance of this is well described by Knight et al (2011) "Up to that point the benefits of economic growth can accrue in the form of the absorption of surplus labour and not in the form of generally rising real incomes. Beyond that point the scarcity of labour can be a powerful force for the reduction of inequality in labour income."

There have been many estimations of surplus labour, where China is at in terms of stages of the economic development and whether the Lewis turning point has been reached. Much of the scholarship, including Lewis himself, has been rather vague on the microeconomic foundations of the surplus labour, the stages of the economic development and the Lewis turning point. Although Fei and Ranis (1964, 1997) discussed three stages of economic development, which implicitly implies two turning points, the literature has continued to proceed as if there is only one turning point to be considered. The lack of microfoundations has hampered the advancement of our understanding of these issues and makes the coexistence of large amount of surplus labour and increasing wage rates in both industrial and agricultural sectors rather puzzling. This paper has built upon Wang and Piesse (2011) and focuses on empirical and practical issues, clarifying the issues involved in estimating surplus labour and the Lewis turning points.

In the previous literature the estimations based on employment data have shown the existence of surplus labour, whilst the estimation based on wage date have shown labour shortage. We have made it clear that an increasing wage, no matter whether it is 
in the industrial sector or in the agricultural sector, does not necessarily mean labour shortages and that the Lewis turning point has been passed. That is, these are neither adequate nor sufficient conditions for testing the Lewis turning point. Indeed, as our theory predicts, when a country passes the first Lewis turning point wages in both sectors are likely to increase, until the type II surplus labour becomes exhausted.

Because both surplus labour and the Lewis turning points are dynamic, many factors need to be taken into consideration in their estimation. In general, the speed of industrial expansion is faster than the population increase in the rural sector, the resulting trend is that the surplus labour would become smaller and the two Lewis turning points will be passed. However, as discussed above, the reaching and passing of these turning points is not likely to be a smooth linear process. Surplus labour may be increased after a positive shock on agricultural productivity. When the industrial sector creates more employment for example as a result of increase in demand for its output, then the speed towards the Lewis turning points may be faster.

It is our view that China has past the first Lewis turning point and our prediction that given the likely population growth, rate of agriculture technological adoption, the growth of the industrial sector and the nature of technical change there, we predict that it will take China at least ten years to exhausts its surplus labour and reach the second Lewis turning point. 


\section{References}

Cai, Fang. 2010, "Demographic transition, demographic dividend, and Lewis turning point in China", China Economic Journal, 3 (2): 107-119.

Cai, Fang and Yang Du, 2011, "Wages increase, wages convergence, and Lewis turning point in China", China Economic Review, 22(4): 601-610

Cai, Fang and Meiyan Wang, 2008, "A Counterfactual Analysis on Unlimited Surplus Labor in Rural China," China \& World Economy, 16 (1): 51-65.

Chan, K. W., 2010, “A China Paradox: Migrant Labor Shortage Amidst Rural Labor Supply Abundance”, Eurasian Geography \& Economics, 51 (4): 513-531.

Du, Yang and Meiyan Wang, 2010, "Discussions on potential bias and implications of Lewis turning point” China Economic Journal, 3 (2): 121 - 136.

Ercolani, Marco G. And Zheng Wei, 2010, "An Empirical Analysis Of The Lewis-Ranis-Fei Theory Of Dualistic Economic Development For China", Discussion Papers 10-06, Department of Economics, University of Birmingham, http://www.economics.bham.ac.uk/research/2010-discussion/10-06.pdf

Fei, John C. H. and Ranis, Gustav. (1964). Development of the Labor Surplus Economy: Theory and Policy, Homewood, IL: Richard A. Irwin, Inc.

Fei, John C. H. and Ranis, G. (1997). Growth and Development from an Evolutionary Perspective, Oxford: Blackwell.

Fleisher, Belton M. Robert Fearn, Zhen Ye, 2011 "The Lewis Model Applied to China: Editorial Introduction to the Symposium" China Economic Review, 22 (4): 535-541

Garnaut, Ross. and Song, L., (editors), 2006, The Turning Point in China's Economic Development, Asia Pacific Press, The Australian National University, Canberra.

Garnaut, Ross. and Huang, Y., 2006, "Continued Rapid Growth and the Turning Point in China's Economic Development", in R. Garnaut and L. Song (eds), The Turning Point in China's Economic Development, Asia Pacific Press, The Australian National University, Canberra.

Garnaut, Ross. 2010, Macro-economic implications of the turning point, China Economic Journal, 3 (2), 181 - 190

Ge, Suqin and Dennis Tao Yang, 2010 "Labor Market Developments in China: A Neoclassical View", China Economic Review, 22(4): 611-625

Golley, Jane. and Xin Meng, 2011, Has China run out of surplus labour? China Economic Review, 22(4): 555-572

Huang, Yiping and Tingsong Jiang, 2010, What Does the Lewis Turning Point Mean for 
China? A Computable General Equilibrium Analysis. China Economic Journal, 3 (2), $191-207$.

Knight, John, and Lina Song, (1999). The rural-urban divide. Economic disparities and interactions in China. Oxford: Oxford University Press.

Knight, John, and Lina Song, (2005). Towards a labour market in China. Oxford: Oxford University Press.

Knight, John, Quheng Deng and Shi Li, 2011, "The Puzzle of Migrant Labour Shortage and Rural Labour Surplus in China”, China Economic Review. 22(4): 585-600

Kwan Fung, 2009, "Agricultural Labour and the Incidence of Surplus Labour: Experience from China during Reform", Journal of Chinese Economic and Business Studies, 7 (3), $341-361$.

Lewis, A. (1954), "Economic Development with Unlimited Supplies of Labour", The Manchester School, 28 (2), 139-191.

Lin, Justin Yifu, 1988. "The Household Responsibility System in China's Agricultural Reform: A Theoretical and Empirical Study", Economic Development and Cultural Change, 36(3): S199-224, Supplement.

National Bureau of Statistics of China (NBS), (eds.), (2010), China Statistic Yearbook, 2010, Beijing: China Statistics Press.

Ranis, G. and Fei, J. C. H. 1961, “A Theory of Economic Development”, American Economic Review, 51, 533-565.

Wang, Meiyan. 2010, "The rise of labor cost and the fall of labor input: Has China reached Lewis turning point?” China Economic Journal, 3 (2), 137 - 153

Wang, Xiaobing and Jenifer Piesse, 2011, "The Micro foundations of Dual Economy Models" The Manchester School, in Press, dio:10.1111/j.1467-9957.2011.02263.x

Zhang, Xiaobo., Jin Yang and Shenglin Wang, 2011. "China has Reached the Lewis Turning Point", China Economic Review, 22(4): 542-554 